\begin{tabular}{lcl}
\hline JURNAL ILMIAH MANAJEMEN & ATADBIR & AT TADBI \\
\hline
\end{tabular}

\title{
Pengaruh Mekanisme Good Corporate Governance pada Pengungkapan Tanggung Jawab Sosial Perusahaan Yang Tergabung Dalam Indeks Kompas 100.
}

Yuliani

Dosen ASMI Citra Nusantara di Banjarmasin

Jl. Soetoyo S. No. 197 Banjarmasin

Email: yuliani57@gmail.com

\begin{abstract}
The purpose of this study was to analyze the effect, good corporate governance mechanism through the composition of the independent board, independent audit committee composition and public ownership, on the disclosure of social responsibility (CSRI). This study also uses a variable sized firms, leverage and profitability as the control variables. The population used a company registered in the Kompas Index 100 period in 2017. The sample was taken by purposive sampling method, and which meet the criteria of sample selection. The samples used were 81 companies. Data collected through secondary data in the form of annual reports published in the period 2017 Indonesian Stock Exchange in 2018. Statistical testing method using multiple linear regression analysis, the statistical test of hypothesis testing and statistical test $t F$. The results of the analysis based on the use of all the independent variables and the control variables show that only the composition of the independent board and size significantly influence the company's CSR disclosure.
\end{abstract}

Key words: Corporate Social Responsibility; Good Corporate Governance Mechanism; Company Size, Leverage, Profitability

\begin{abstract}
ABSTRAK
Penelitian bertujuan menganalisis pengaruh mekanisme good corporate governance melalui komposisi dewan komisaris independen, komposisi komite audit independen, dan kepemilikan publik, terhadap pengungkapan tanggung jawab sosial (CSRI). Penelitian ini juga menggunakan variabel ukuran perusahaaan, leverage dan profitabilitas sebagai variabel kontrol. Populasi yang digunakan perusahaan yang terdaftar dalam Indkes Kompas 100 periode pada tahun 2017. Sampel diambil dengan metode purposive sampling, dan yang memenuhi kriteria pemilihan sampel. Sampel yang digunakan sebanyak 81 perusahaan. Data dikumpulkan melalui pengambilan data sekunder berupa laporan tahunan perusahaan periode 2017 yang dipublikasikan di Bursa Efek Indonesia tahun 2018. Metode pengujian statistik menggunakan Analisis Regresi Linear Berganda, dengan pengujian hipotesis uji statistik $t$ dan uji statistik F. Hasil analisis berdasarkan penggunaan semua variabel independen dan variabel kontrol menunjukkan bahwa komposisi dewan komisaris independen, komposisi komite dan ukuran perusahaan berpengaruh signifikan terhadap pengungkapan CSR.
\end{abstract}

Kata-kata kunci : Corporate Social Responsibility, Mekanisme Good Corporate Governance, Ukuran Perusahaan, Leverage, Profitabilitas 


\section{PENDAHULUAN}

Pelaksanaan good corporate governance di Indonesia menjadi sorotan utama, terlebih semenjak pemberlakuan Undang Undang Perseroan Terbatas (UUPT) terbaru No. 40 tahun 2007. Kesadaran para manajemen terhadap kewajiban mereka, dalam menjalankan sebuah tata kelola perusahaan yang baik, demi memaksimalkan ekspektasi dari pemegang saham, atas investasi yang mereka tanamkan sebagai sebuah prestasi manajemen (Hapsoro, 2007).

Penilaian prestasi manajemen tersebut, tidak hanya dilihat melalui prestasi financial seperti mampu memaksimalkan laba bagi pemegang saham (stockholder), tapi juga mampu mempertahankan kelangsungan hidup perusahaan jangka panjang. Prestasi yang kedua tersebut, hanya akan terjadi pada saat manajemen perusahaan mampu menyeimbangkan hak dan kewajibannya, baik kepada para pemegang saham (stockholder) maupun kepada para pemangku kepentingan lainnya yang berasal dari luar/umum (stakeholder). Hal inilah yang dituntut sebagai salah satu dari implementasi pelaksanaan good corporate governance (tata kelola yang baik) bagi perusahaan sebagai bentuk pertanggung jawaban, atas kinerja perusahaan yang selama ini mereka jalankan (Jalal, 2012).

Implementasi good corporate governance yang salah satunya adalah dengan adanya pengungkapan CSR (corporate social responsibility) dalam penyajian laporan tahunan perusahaan, menjadi sebuah hal yang wajib bagi perusahaan. Praktek dan pengungkapan CSR dipandang sebagai implementasi konsep GCG yang diwujudkan dalam kepentingannya dalam memperhatikan pihak luar perusahaan (stakeholders) dengan pertimbangan keuntungan perusahaan jangka panjang, khususnya memunculkan image perusahaan yang bertanggung jawab terhadap lingkungan. Good corporate governance (GCG) sendiri dinilai sebuah kegiatan yang mutlak dilakukan untuk mengukur kinerja perusahaan dalam bidang apapun.

Dalam kegiatannya, sebuah mekanisme penerapannya disusun, sebagai bagian dari implementasi GCG. Perbedaan pandangan manajemen berdasarkan ekspektasi stockholder dan stakeholder yang kemudian diusahakan pemenuhannya secara berimbang. Hal ini akan membuat CSR dianggap sebagai sebuah kepantasan yang layak bagi stakeholder sehingga dalam jangka panjang lingkungan sekitar masih dalam keadaan kondusif.

Dalam tataran tertinggi perusahaan, dewan komisaris sebagai salah satu mekanisme GCG yang dibentuk dalam rangka memberikan pengawasan serta memberikan pertunjuk dan arahan kepada pengelola perusahaan yang disebut sebagai pihak manajemen. FCGI (2002) menyatakan bahwa manajemen bertanggung jawab dalam rangka meningkatkan efisiensi dan daya saing perusahaan, sedangkan dewan komisaris bertanggungjawab dan memastikan bahwa kegiatan manajemen berjalan sebagaimana mestinya. Beberapa penelitian yang dilakukan selama ini memiliki beragam hasil, dimana Badjuri (2010), Nurkhin (2010), dan Diyanti (2011) mendukung pernyataan tersebut, dan menemukan bahwa terjadi hubungan positif antara dewan komisaris independen dengan pengungkapan tanggung jawab sosial. Beasley (1996) bahkan menyatakan bahwa besarnya proporsi dewan komisaris independen yang dimiliki perusahaan secara signifikan mengurangi tingkat kecurangan yang dilakukan manajemen, dibandingkan dengan perusahaan yang tidak memiliki dewan komisaris independen. Namun pernyataan tersebut tidak ditemukan pada penelitian Said, dkk (2009), Sudana dan Arlindania (2011) dan Rawi (2008), yang menghasilkan kesimpulan bahwa ada atau tidak adanya dewan komisaris independen ternyata tidak mempengaruhi terhadap pengungkapan sosial yang dilakukan oleh perusahaan dalam laporan tahunan. 
Mekanisme GCG lainnya yang diwajibkan oleh Bursa Efek Indonesia bagi para emitennya selain harus adanya dewan komisaris independen adalah adanya komite audit independen. Secara empiris, Klein (2002) menyatakan bahwa perusahaan yang memiliki komite audit independen cenderung melaporkan laba dengan kandungan penyimpangan atau manipulasi data (discretionary accruals) yang lebih kecil dibandingkan dengan yang tidak memiliki komite audit independen. Dalam penelitian Ho dan Wong (2000) ditemukan bahwa keberadaan komite audit independen memiliki hubungan positif dan signifikan terhadap tingkat pengungkapan sosial. Demikian pula hasil yang dikemukakan oleh Diyanti (2010) dan Said dkk (2009), namun tidak demikian dengan penelitian yang dilakukan oleh Mohd-Nasir dan Abdullah (2004), Junaid (2004) dan Akhtaruddin (2009).

Proses pengawasan yang baik akan memotivasi perusahaan untuk selalu mematuhi peraturan dan melakukan pengungkapan sesuai dengan peraturan yang diberlakukan baik dari pemerintah, lembaga keuangan maupun bagi berbagai kepentingan baik shareholders maupun stakeholders. Pengungkapan informasi dan transparansi yang lengkap dilakukan oleh perusahaan diperlukan guna menghasilkan informasi yang relevan dan dapat dipercaya. Berkaitan dengan hal tersebut, maka struktur kepemilikan menjadi mekanisme GCG lainnya yang banyak diteliti terkait dengan pengungkapan tanggung jawab sosial. Struktur kepemilikan yang dimiliki oleh perusahaan bisa berasal dari manajemen, institusional, kepemilikan domestik, kepemilikan asing maupun kepemilikan publik.

Dalam kepemilikan publik Hapsoro (2007) bahkan menyatakan hubungan variabel ini positif pada pengungkapan yang bersifat wajib (mandatory disclosure) maupun yang bersifat sukarela (voluntary disclosure) pada pengungkapan sosial perusahaan di Indonesia. Hasil berbeda dikemukakan oleh Marzully dan Priantinah (2002) dan Hosain, dkk (1994) yang menemukan hubungan yang negatif antara struktur kepemilikan publik dengan tingkat pengungkapan.

Penelitian ini termotivasi dengan adanya tidak-konsistennya hasil yang dipaparkan beberapa peneliti untuk menguji mekanisme GCG terhadap pengungkapan CSR. Variabel yang dipilih dalam mekanisme GCG yang dipakai antara lain faktor komposisi dewan komisaris independen, komposisi audit independen, dan struktur kepemilikan publik. Sedangkan penggunaan ukuran perusahaan, rasio leverage dan tingkat profitabilitas yaitu return on assets (ROA) dipakai sebagai variabel kontrol. Variabel kontrol dipakai agar dapat menetralisir pengaruh variabel luar yang tidak diperlukan, dan atau menjembatani hubungan antara variabel independen dan variabel dependen, selain berguna untuk meminimalisir adanya kemungkinan kesalahan pengambilan keputusan.

Penelitian ini bertujuan untuk mengetahui pengaruh Pengaruh Mekanisme Good Corporate Governance pada Pengungkapan Tanggung Jawab Sosial Perusahaan Yang Tergabung Dalam Indeks Kompas 100. Pemilihan Indeks Kompas 100 dilakukan sebagai pembeda dengan objek penelitian sebelumnya, alasan lainnya adalah karena Kompas sebagai salah satu media informasi terbesar di Indonesia, yang memiliki kewenangan berdasarkan peraturan BEJ pada tanggal 13 Juli 2007, untuk dapat mengeluarkan list 100 perusahaan terbaik versi kompas yang dinilai memiliki pertimbangan atas kinerja yang baik. Kinerja yang dimaksudkan antara lain faktor likuiditas, kapitalisasi saham dan kinerja fundamental dari saham-saham tersebut, dengan review yang dilakukan setiap 6 (enam) bulan sekali. Indeks ini termasuk indeks yang jarang untuk diteliti, padahal faktor publikasi yang dilakukan oleh perusahaan tergantung pada media baik cetak maupun elektronik. 
Penelitian ini bermanfaat untuk memberikan kontribusi tentang efektifitas pelaksanaan pengungkapan CSR di Indonesia khususnya Perusahaan yang tergabung dalam Indeks Kompas 100 setelah adanya UU No. 40 tahun 2007.

\section{TINJAUAN PUSTAKA}

Landasan Teori

Teori Legitimasi

Kesadaran perusahaan bahwa kelangsungan hidup perusahaan juga tergantung dalam hubungan antara perusahaan dengan lingkungan sekitar dimana perusahaan beroperasional, hal ini menegaskan teori legitimasi sebagai bagian kontrak sosial. Dimana jika terjadi hilangnya legitimasi perusahaan dalam sistem nilai masyarakat, maka akan berlanjut dengan terancamnya kelangsungan hidup perusahaan (Haniffa dan Cooke, 2005)

CSR dinilai sebagai sebuah komunikasi antara pihak organisasi atau perusahaan dengan masyarakat dan sosial, sehubungan dengan jalinan komunikasi mengenai dampak sosial dan lingkungan. Sebagai akibat dilaksanakannya kegiatan operasional organisasi atau perusahaan yang selama ini dijalankannya (Hackston dan Milne, 1996).

Corporate Social Responsibility dan Mekanisme Good Corporate Governance

Good corporate governance (GCG) diartikan sebagai rangkaian mekanisme yang dapat melindungi pihak-pihak minoritas (outside investor/minority shareholder) dari eksplorasi yang dilakukan para manager dan pemegang saham kendali (insiders) dengan adanya penekanan pada mekanisme legal (Shleifer dan Vinshy, 1997). Pelaksanaan corporate governance yang baik (good corporate governance), juga didukung oleh pemerintah dengan mengeluarkan beberapa peraturan terkait adanya mekanisme GCG yang dibentuk sebagai upaya pelaksanaan GCG.

Pengembangan Hipotesis
Pengaruh Dewan Komisaris Independen dengan pengungkapan tanggung jawab perusahaaan

Bhojraj dan Sengupta (2003) mengungkapkan, bahwa perusahaan dengan proporsi dewan komisaris independen lebih besar akan memiliki tata kelola (corporate governance) yang lebih baik. Hanifa dan Cooke (2005) menyampaikan bahwa usaha dewan komisaris independen memberikan tekanan pada perusahaan publikasi atau pengungkapan aktifitas perusahaan dalam laporan tahunan, merupakan kegiatan menyelaraskan antara keputusan organisasi, tindakan perusahaan dengan nilai-nilai sosial dan legitimasi perusahaan. Peranan positif terhadap keberadaan komisaris independen membentuk hipotesis pertama yaitu;

$\mathrm{H}_{1}=$ Dewan komisaris independen berpengaruh positif terhadap pengungkapan tanggung jawab sosial perusahaan.

\section{Pengaruh Komite Audit Independen Terhadap Pengungkapan Tanggung Jawab Sosial Perusahaaan}

Vicknair et al. (1993) menemukan proporsi atau susunan dari anggota komite audit yang dimiliki oleh perusahaan publik, memiliki proses pengawasan terhadap kinerja perusahaan yang lebih baik dari yang tidak memiliki komite anggota komite audit independen. Berdasarkan peranan positif yang diciptakan akibat keberapaan pengawasan internal dalam hal ini komite audit diperusahaan, dan peranan komite audit independen sebagai personal yang bebas dari pengaruh beberapa pihak yang berkepentingan, maka hipotesis kedua yang bisa dibentuk yaitu;

$\mathrm{H}_{2}=$ Komite Audit independen berpengaruh positif terhadap pengungkapan tanggung jawab sosial perusahaan. 
Pengaruh Struktur Kepemilikan Publik Terhadap Pengungkapan Tanggung Jawab Sosial Perusahaan

Pengaruh struktur kepemilikan Korporasi akan mempengaruhi sifat permasalahan keagenan yang terjadi antara manajer dengan pemegang saham luar (outside shareholders) dan antar pemegang saham (Jensen dan Meckling 1972). Dalam situasi terjadi konflik, pemegang saham publik (masyarakat) diasumsikan akan memiliki keinginan dan kemampuan lebih besar dalam rangka memonitoring secara ketat terhadap kinerja perusahaan, serta dalam rangka mendisiplinkan manajemen.

Berdasarkan uraian di atas, maka hipotesis yang diajukan dalam penelitian ini adalah:

$\mathrm{H}_{3}=$ Struktur Kepemilikan Publik berpengaruh positif terhadap pengungkapantanggung jawab sosial perusahaan.

Pengaruh Ukuran Perusahaan terhadap Pengungkapan Tanggung Jawab Sosial Perusahaan

\section{Dalam Sembiring}

pengungkapan informasi yang lebih besar merupakan salah satu cara dalam mengurangi adanya biaya politis sebagai bagian dari aplikasi tanggung jawab perusahaan Belkaoui dan Karpik (1989), Hackstone dan Milne (1996) sebelumnya juga menegaskan hal yang sama, bahwa ukuran perusahaan berpengaruh signifikan terhadap pengungkapan tanggung jawab sosial. Berdasarkan uraian di atas, maka hipotesis yang diajukan dalam penelitian ini adalah sebagai berikut:

$\mathrm{H}_{4}=$ Ukuran Perusahaan berpengaruh positif terhadap pengungkapan tanggung jawab sosial perusahaan.

Pengaruh Tingkat Leverage terhadap Pengungkapan Tanggung Jawab Sosial Perusahaan.

Sembiring (2005) menyatakan bahwa tingkat rasio keuangan ini memiliki pengaruh negatif terhadap pengungkapan tanggung jawab perusahaan. Sejalan dengan Belkoui dan Karpik (1989) yang menyatakan semakin besar tingkat leverage semakin besar perusahaan akan berusaha melanggar perjanjian kredit, dan cenderung melaporkan laba sekarang lebih tinggi dengan cara mengurangi biayabiaya, termasuk biaya untuk mengungkapkan informasi tanggung jawab sosial. Berdasarkan hal tersebut maka hipotesis ke lima yaitu:

$\mathrm{H}_{5}=$ Rasio Leverage berpengaruh negatif terhadap pengungkapan tanggung jawab sosial perusahaan.

\section{Pengaruh Profitabilitas terhadap Pengungkapan Tanggung Jawab Sosial Perusahaan}

Faktor profitabilitas disebut sebagai salah satu faktor yang Membuat manajemen berperilaku bebas dan fleksibel dalam hal mengungkapkan tanggung jawab sosial kepada para shareholeders (Hackstone dan Milne, 1996). Anggraini (2006) menyatakan semakin tinggi nilai profitabilitas semakin besar pengungkapan tanggung jawab sosial. Berdasarkan uraian di atas, maka hipotesis selanjutnya adalah

$\mathrm{H}_{6}=$ Rasio Profitabilitas berpengaruh positif terhadap pengungkapan tanggung jawab sosial perusahaan.

\section{METODE PENELITIAN}

\section{Populasi, Sampel dan Teknik Pengumpulan data}

Penelitian ini mengambil populasi berupa seluruh laporan tahunan perusahaan yang menjadi emitem Bursa Efek Indonesia yang dikategorikan dalam indeks kompas 100 tahun 2014 yaitu sebanyak 100 perusahaan. Teknik pengambilan sample menggunakan metode purposive sampling dengan tujuan agar terjadi kesesuaian dengan sample yang dipilih. Secara singkat pengambilan sampel. 
Tabel 1. Sampel Penelitian

\begin{tabular}{llc}
\hline No & Keterangan & Jumlah \\
\hline 1 & Jumlah Perusahaan & 100 \\
2 & Perusahaan tidak konsisten bergabung dalam indeks kompas 100 periode & $(13)$ \\
& Februari-Juli 2016 dan periode Agustus 2016-Januari 2017 & $(6)$ \\
3 & Perusahaan yang memiliki leverage dan atau ROA yang negatif & 81 \\
\hline & Jumlah Perusahaan yang menjadi sampel &
\end{tabular}

\section{Definisi Operasional}

Tabel 1.2 Definisi Operasional Variabel

\begin{tabular}{lll}
\hline Variabel dependen & Definisi Operasional & \multicolumn{1}{c}{ Pengukuran } \\
\hline CSRD & $\begin{array}{l}\text { Pengungkapan Sosial Perusahaan menurut CSRD } \\
\text { yang diisyaratkan GRI (79 item) }\end{array}$ & $\begin{array}{l}\text { Jumlah } \\
\text { Diungkapkan }\end{array}$ \\
\hline Variabel Independen & Mekanisme Good Corporate Governance & item \\
\hline $\begin{array}{l}\text { Dewan Komisaris Independen } \\
\text { (KOM_IND) }\end{array}$ & $\begin{array}{l}\text { Anggota komisaris yang berasal dari luar kalangan } \\
\text { perusahaan dan mampu bersikap independen }\end{array}$ & $\begin{array}{l}\text { Jumlah komisaris } \\
\text { Independen }\end{array}$ \\
& & total dewan \\
Komite Audit Independen & Anggota komite yang merupakan anggota komite & komisaris. \\
(AUD_IND) & audit yang berasal dari luar emiten & Jumlah Kom-ite \\
& & audit independen \\
Struktur kepemilikan saham & Kepemilikan saham yang dimiliki oleh publik & Total komite audit. \\
publik & & Total Saham Publik \\
(PUB) & & Total Saham \\
\hline VARIABLE KONTROL & KARAKTERISTIK PERUSAHAAN & \\
\hline SIZE (ukuran Perusahaan) & Skala yang dipakai dalam menentukan besar kecilnya & Log (natural \\
& ukuran perusahaan, salah satunya dengan Log total & Logaritma) dari total \\
& aktiva & Asset \\
LEV (Rasio leverage) & Aspek fundamental yang digunakan untuk mengetahui & Total Liabilities \\
PROF (Profitabilitas) & sejauh mana perbandingan antara hutang dan modal & Total Equity \\
& Menggunakan pengukuran Return On Assets (ROA) & Earning After Tax \\
\hline untuk mengetahui & Total Asset
\end{tabular}

Sumber: Data diolah, 2018

\section{Metode dan Analisis Data}

Uji Asumsi Klasik

Uji Normalitas

Pengujian terhadap normal atau tidaknya distribusi data dalam model regresi dan data residual, maka pengujian dilakukan dengan melakukan uji analisis statistik (Ghozali, 2005). Pengujian tersebut dilihat dari Kolmogorov-Smirnov test (K-S).

Uji Multikolinearitas

Uji multikolinearitas dilakukan untuk mengetahui apakah setiap variabel independen saling berhubungan secara linear. Acuan nilai cut off yang dipakai umumnya, jika nilai tolerance $>10$ dengan nilai $\mathrm{VIF}<10$, maka disimpulkan bahwa tidak terjadi multikolinearitas antar variabel independen dalam model regresi, namun jika nilai tolerance $>10$ dengan nilai VIF $>10$, maka disimpulkan bahwa ada multikolinearitas antar data.

Uji Autokolerasi

Autokorelasi muncul karena observasi yang berurutan sepanjang waktu berkaitan satu sama lain (Ghozali, 2005). Uji autokorelasi dalam penelitian ini dilakukan dengan menghitung nilai Durbin Watson Test. Apabila angka dalam model regresi berada diatas -2 dan berada di bawah +2 maka berarti tidak terjadi autokolerasi antara variabel yang diteliti.

Uji Heterokedastisitas

Pengujian dilakukan melalui uji glejser dengan menguji variabel dengan 
melakukan regresi antara variabel independen dengan nilai absolute residualnya. Apabila nilai signifikan yang dihasilkan setiap variabel independen yang

diuji bernilai diatas 5\%, maka dapat disimpulkan tidak terjadi heterokedastisitas dalam pengujian variabel.

\section{Analisis Deskriptif}

Tabel 3. Hasil Analisis Deskriptif

\begin{tabular}{lrrrrr}
\multicolumn{6}{c}{ Descriptive Statistics } \\
\hline & N & \multicolumn{1}{c}{ Min. } & \multicolumn{1}{c}{ Max. } & \multicolumn{1}{c}{ Mean } & Std. Deviation \\
\hline Kom_Ind & 81 & 17.00 & 80.00 & 42.5438 & 13.78653 \\
Audit_Ind & 81 & 20.00 & 67.00 & 35.9194 & 9.64291 \\
Shm_Publik & 81 & 4.50 & 85.30 & 41.8493 & 15.17845 \\
Size & 81 & 12.81 & 22.95 & 17.1688 & 1.67943 \\
Lev & 81 & 0.90 & 119.10 & 18.7054 & 24.74689 \\
Prof & 81 & 0.25 & 37.05 & 6.6435 & 6.44375 \\
CSRD & 81 & 65.82 & 91.14 & 78.9349 & 6.88280 \\
Valid N (listwise) & 81 & & & & \\
\hline
\end{tabular}

Sumber: Data diolah (2018)

\section{Hasil Uji Regresi Berganda}

Hasil perhitungan analisi regresi berganda menunjukan bahwa variabel independen yang diproksi melalui dewan komisaris independen, komite audit independen, struktur kepemilikan publik dan struktur kepemilikan manajerial, beserta variabel kontrol melalui perhitungan ukuran perusahaan, leverage dan nilai profitabilitas menunjukan hasil yang dapat disusun model regresi linear berganda yaitu: $\mathrm{Y}=48,294+0,163 \mathrm{KOM}$ IND + 0,057AUDIT + $0,015 \mathrm{PUB}+0,170 \mathrm{SIZE}+0,046 \mathrm{LEV}+$ $0,007 \mathrm{PROF}$

Nilai konstansta yang menunjukan nilai 48,294 menyatakan bahwa variabel independen dianggap konstan, maka ratarata pengungkapan tanggung jawab sosial dinilai 48,294\%.

\section{Hasil Pengujian Hipotesis}

Variabel yang memiliki pengaruh positif dan signifikan terhadap pengungkapan CSR yang dibuktikan dengan nilai signifikan di bawah 5\% antara lain adalah; Proporsi Komisaris Independen dengan nilai 0,003, serta Ukuran Perusahaan dengan nilai 0,008. Sedangkan variabel yang lain tidak menunjukan hasil yang signifikan. Hasil uji t disajikan dalam tablel berikut:

Tabel 4. Hasil Uji t (t test)

\begin{tabular}{|c|c|c|c|c|c|c|}
\hline \multicolumn{7}{|c|}{ Coefficients $^{\mathbf{a}}$} \\
\hline & & \multicolumn{2}{|c|}{ Unstandardized Coefficients } & \multirow{2}{*}{$\begin{array}{c}\text { Standardized } \\
\text { Coefficients } \\
\text { Beta }\end{array}$} & \multirow[b]{2}{*}{$\mathrm{t}$} & \multirow[b]{2}{*}{ Sig. } \\
\hline \multicolumn{2}{|c|}{ Model } & $\mathrm{B}$ & Std. Error & & & \\
\hline 1 & (Constant) & 48.294 & 8.329 & & 5.798 & 0.000 \\
\hline & Kom_Ind & 0.163 & 0.053 & 0.326 & 3.091 & 0.003 \\
\hline & Audit_Ind & 0.057 & 0.071 & 0.080 & 0.815 & 0.418 \\
\hline & Shm_Publik & 0.015 & 0.045 & 0.034 & 0.346 & 0.730 \\
\hline & Size $^{-}$ & 1.170 & 0.432 & 0.286 & 2.707 & 0.008 \\
\hline & Lev & 0.046 & 0.031 & 0.166 & 1.477 & 0.144 \\
\hline & Prof & 0.007 & 0.110 & 0.007 & 0.065 & 0.948 \\
\hline
\end{tabular}

a. Dependent Variable: CSRD

Sumber : Data diolah (2018) 


\section{HASIL DAN PEMBAHASAN}

Berdasarkan pengamatan terhadap seluruh sampel yang diuji sebanyak 81 perusahaan, maka diperoleh hasil secara content analysis seperti yang tercantum dalam tabel 1.3 sebelumnya, bahwa nilai rata-rata pengungkapan tanggung jawab sosial perusahaan yaitu 78,94 atau 78,94\%. Angka tersebut mengindikasikan bahwa tingkat pengungkapan tersebut sudah bagus, dengan nilai tertinggi yaitu 91,14 dan nilai terendah yaitu 65,82 . Rata-rata nilai pengungkapan tingkap pelaporan CSR di Indonesia yang mencapai lebih dari $50 \%$ mengindikasikan bahwa perusahaan - perusahaan di Indonesia semakin menyadari bahwa penerapan good corporate governance dalam kegiatan perusahaan melalui corporate social resposibility memberikan feedback yang bagus bagi kelangsungan hidup perusahaan.

Dari hasil pengujian diketahui bahwa penelitian ini konsisten dengan penelitian Sembiring (2007), Nurkhin (2010) dan Diyanti (2010) yang menyatakan ada hubungan positif dan signifikan antara pelaporan CSR dengan tingkat dewan komisaris independen yang dimiliki sebuah perusahaan. Namun tidak konsisten dengan hasil penelitian Ho dan Wong (2000), Diyanti (2010) dan Said, dkk (2009) yang menyatakan bahwa ada hubungan positif terhadap ukuran Komite Audit Independen. Ketidak konsistenan hasil ditemukan dengan hasil penelitian Diyanti (2010) dan Rawi (2008), mengenai pengaruh leverage terhadap CSR.

Penelitian terhadap struktur kepemilikan baik publik juga tidak menemukan hubungan sama seperti penelitian Hapsoro (2007). Padahal beberapa pendapat menyatakan bahwa semakin banyak proporsi yang dimiliki oleh publilk atas saham suatu perusahaan, maka tingkat pengawasan dan pengendalian masyarakat juga akan meningkat.
Dari variabel penelitian ukuran perusahaan ditemukan hasil yang konsisten dengan penelitian Belkaoui dan Karpik (1989), Hackstone dan Milne (1996) dan Sembiring (2005) yang berpengaruh positif terhadap CSR. Sedang dari sisi profitabilitas tidak menemukan hubungan dengan pengungkapan CSR yang tidak sejalan dengan Hackson dan Milne (1996) dan Hosain dkk (2006).

\section{KESIMPULANDAN SARAN Kesimpulan}

Dari keenam faktor yang diuji hanya Proporsi Komisaris Independen, dan Ukuran Perusahaan yang berpengaruh signifikan terhadap pengungkapan CSR. Hal ini mengindikasikan bahwa pengawasan yang dilakukan oleh pihak dewan komisaris akan berjalan efektif, apabila struktur personal yang independen dalam dewan komisaris semakin besar. Demikian pula ukuran perusahaan yang dinilai mampu memotivasi luas pengungkapan CSR yang dilakukan akibat besarnya ukuran perusahaan berbanding lurus dengan semakin tingginya tuntutan pengungkapan dari berbagai pihak.

\section{Implikasi Penelitian}

Pihak-pihak dalam perusahaan yang rentan dengan terjadinya konflik keagenan (agency problem), melalui adanya mekanisme GCG dinilai mampu mengendalikan pihak-pihak yang terlibat dan memiliki kepentingan dalam mengelola perusahaan. Lima Prinsip yang diterapkan dalam good corporate governance sesuai dengan lima prinsip yang dijalankan yaitu keterbukaan, akuntabilitas, tanggung jawab, indenpendensi dan kewajaran, dinilai mampu memperbaiki citra perusahaan. Peranan aktif semua pihak terutama pihak komisaris yang berperan aktif serta bersikap independen. Oleh karena itu, tuntutan akan struktur, sistem dan proses yang memadai pada setiap kegiatan yang 
dilakukan mekanisme GCG diharapkan mampu membawa perusahaan dalam tujuan penerapan GCG yang optimal dan efektif. Keberlanjutan pelaksanaan GCG dalam perusahaan bisa dilakukan dalam beberapa tindakan nyata, antara lain penetapan visi, misi dan corporate value yang menjadikan pilar utama perusahaan.

\section{Saran}

Penggunaaan jumlah pengamatan yang lebih luas, tidak hanya 1 (satu) tahun agar menghasilkan data yang lebih komprehensif mengingat penerapan mekanisme GCG maupun praktek pelaksanaan CSR sudah lama dikembangkan di Indonesia. Serta variabel yang berpengaruh secara positif dan signifikan pada penelitian ini yaitu dewan komisaris independen, dan ukuran perusahaan dapat menjadi bahan penelitian lanjutan dengan menambahkan variabel lain yang dinilai mampu mempengaruhi pengungkapan tanggung jawab sosial perusahaan, sehingga memperluas temuan faktor yang dapat mempengaruhi CSR.

\section{DAFTAR PUSTAKA}

Anggraini, Fr. Reni Retno, 2006, Pengungkapan Informasi Sosial dan Faktor-Faktor yang mempengaruhi Pengungkapan Informasi Sosial dalam Laporan Keuangan Tahunan (Studi Empiris pada Perusahaan-Perusahaan yang terdaftar Bursa Efek Jakarta), Simposium Nasional Akuntansi 9, Padang.

Badjuri, Ahmad, 2011. Faktor-faktor fundamental, mekanisme corporate governance, pengungkapan Corporate Social Responsibility (CSR) perusahaan manufaktur dan Sumber Daya Alam di Indonesia, Dinamika Keuangan dan Perbankan Vol 3 No1.

Belkaoui, A. Dan PG. Karpik. 1989. "Determinats of the corporate decision to disclose social information". Accounting, Auditing and Accountability Journal, Vo. 2, No.1.
Bhojraj, Sanjeev, and Partha Sengupta, 2003, The effect of corporate governance mechanisms on bond ratings and yields: The role of institutional investors and outside directors." The Journal of Business 76, 455-475.

Diyanti, Ferry. 2011. Mekanisme Good Corporate Governance, Karakteristik Perusahaan dan Mandatory Disclosure: Studi Empiris pada Perusahaan manufaktur yang Terdaftar di Bursa Efek Indonesia", Jurnal.

Jalal, 2012, CSR: Keterpaksaan, Kewajiban, Kepantasan, Keniscayaan, Lingkar Studi CSR, Bogor, Indonesia.

Jensen, Michael $C$. and William $H$. Meckling, 1976, Theory of the firm: Managerial behavior, agency costs, and ownership structure, Journal of Financial Economics 3

Imam Ghozali. (2005). Aplikasi Analisis Multivariate dengan Program SPSS, Semarang: Badan Penerbit Universitas Diponegoro

Gray, Rob; Colin Dey; Dave Owen; Richard Evans and Simon Zadek. 1997. Struggling with the praxis of social Accounting: Stakeholders, Accountability, Audits and Procedures. Accounting, Auditing and Accountability Journal.Vol.10, No.3.

Hackston, David and Milne, Marcus J., (1996). "Some Determinants Of Social And Environmental Disclosures In New Zaeland Companies", Accounting, Auditing and Accountability Journal, Vol. 9, No. 1

Hanifa, R.M., dan T.e. Cooke (2005). "The Impact of Culture and Governance on Corporate Social Reporting". Journal of Accounting and Public Policy 24.

Hapsoro, Dody. 2007. Pengaruh Struktur Kepemilikan Terhadap Transparansi" Studi Empiris Di Pasar Modal Indonesia, Jurnal Akuntansi dan Manajemen Vol 12 No. 2, STEI YKPN Yogyakarta 
Ho, Simon S. M. and K. S. Wong (2000)." A Study of the Relationship Between Corporate Governance Structures and the Extent of Voluntary Disclosure". WorkingPaper.

Hossain, M, L. M. Tan, dan M. Adams. 1994. Voluntary Disclosure in an Emerging Capital Market: Some Empirical Evidence from Companies Listed on the Kuala Lumpur Stock Exchange. The International Journal of Accounting.

Kurnianingsih, R. 2000. "Pengaruh Sistem Pengukuran Kinerja dan Sistem Penghargaan terhadap Keefektifan Penerapan Tekhnik Total Quality Manajemen: Studi Empiris Pada Perusahaan Manufactur di Indonesia," Seminar Nasional Akuntansi

Meek, G. K., C. B. Robert and S. J. Gray (1995)."Factors Influencing Voluntary Annual Report Disclosures by US, UK, and Continental Europe Multinational Corp". Journal of International Business Studies Vol. 26

Nasir, Mohd NA. Dan Abdullah S.N. 2004. "Voluntary disclosure and corporate governance among financially distressed firm in Malaysia" Financial Reporting, Regulation and Governance, Vol 3 No 1
Nurkhin, Ahmad, 2010, "Corporate Governance dan Profitabilitas, pengaruhnya terhadap Sosial perusahaan", Jurnal Dinamika Akuntansi Vol 2 No. 1 hal 46-55, UniversitasNegri Semarang

Rawi 2008, Pengaruh kepemilikan manajemen, institusi, dan leverage terhadap corporate social responsibility pada perusahaan manufaktur yang lisiting di Bursa Efek Indonesia, TesisUniversitas Diponegoro, Semarang

Said, Roshima., Yusrie Hj. Zainuddin, dan Hasnah Haron,2009. The relationship between corporate social responsibility and corporate gevernance characteristics in Malaysian Public Listed Companies", Social Responsibility Journal. Vol 5, NO. 2.

Shleifer, Andrei and Robert W. Vishny. 1997. "A Surveyof Corporate Governance".Journal of Finance,52.

Sudana, I Made dan Putu Ayu A., 2011. Corporate Governance dan pengungkapan Corporate Social Responsibility pada perusahaan gopublic di Bursa Efek Indonesia, Jurnal manajemen Teori dan terapan, Tahun 4, No 1

Utama, Sidharta. 2007. "Evaluasi infrastruktur pendukung pelaporan tanggung jawab sosial dan lingkungan di Indonesia". Pidato Ilmiah pengukuhan guru besar FEUI. Jakarta. 